\title{
Research Paper: The Level of Anxiety in Those Participating in Premarital Counseling Classes and Its Relationship With Health Literacy
}

\author{
Neda Raeisi Yekta $^{1}$ (D, Zahra Bozorgi ${ }^{2}$, Elham Charoghchian Khorasani ${ }^{1}$, Hadi Tehrani ${ }^{3}$, Habibollah Esmaily $^{4}$, Mohammad Vahedian-Shahroudi ${ }^{3 *}$ (i) \\ 1. Student Research Committee, Department of Health Education and Health Promotion, School of Health, Mashhad University of Medical Sciences, Mashhad, Iran \\ 2. Department of Psychology, Faculty of Psychology, Al-Zahra University, Tehran, Iran. \\ 3. Department of Health Education and Health Promotion, School of Health, Mashhad University of Medical Sciences, Mashhad, Iran \\ 4. Research Center for Social Factors Affecting Health, School of Health, Mashhad University of Medical Sciences, Mashhad, Iran.
}

\begin{tabular}{|c|c|}
\hline $\begin{array}{l}\text { Use your device to scan } \\
\text { and read the article online }\end{array}$ & Cftation Raeisi Yekta N, Bozorgi Z, Charoghchian Khorasani E, Tehrani H, Esmaily H, Vahedian-Shahroudi M. The Level \\
\hline 口ifing & $\begin{array}{l}\text { of Anxiety in Those Participating in Premarital Counseling Classes and Its Relationship With Health Literacy. Journal of Re- } \\
\text { search \& Health. 2021; 11(4):267-274. http://dx.doi.org/10.32598/JRH.11.4.1856.1 }\end{array}$ \\
\hline 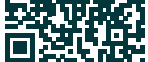 & doi http://dx.doi.org/10.32598/JRH.11.4.1856.1 \\
\hline
\end{tabular}

\section{(i) (5)}

Article info:

Received: 14 Dec 2020

Accepted: 18 May 2021

Publish: 01 Aug 2021

\section{Keywords:}

Counseling, Marriage,

Anxiety, Health literacy

\section{A BSTRACT}

Background: Anxiety is a natural response to risks and a warning sign. Health literacy as an accessible and dynamic tool can play a crucial role in mental health. This study was conducted to determine the relationship between anxiety and health literacy in those participating in premarital counseling classes in Mashhad.

Methods: The present research was a descriptive-analytical study that was conducted in 2019 on 400 individuals participating in premarital classes in comprehensive health centers in Mashhad. Of all men and women participating in premarital classes of Mashhad comprehensive health centers, 400 people were randomly selected from each center (relative to the number of people in each center in the last six months). Data collection tools were the Demographic Information Questionnaire, Beck Standard Anxiety Questionnaire, and Health Literacy Questionnaire for Iranian Adults (HELIA). Data were analyzed using SPSS v. 23 software by Man-Whitney, Kruskal-Wallis, correlation, and regression tests.

Results: In this study, $38.8 \%$ of participants were male and $61.2 \%$ were female. The Mean \pm SD age of participants was $26.8 \pm 14.17$ years, the Mean \pm SD age of men and women was $27.8 \pm 7.2$ and $25.8 \pm 2.5$ years, respectively. According to the Beck Anxiety Questionnaire, anxiety scores ranged from zero to 63 and the Mean \pm SD anxiety was $29.04 \pm 8.3$. The Mean \pm SD anxiety of men was $27.7 \pm 7.8$ and the Mean \pm SD anxiety of women was $29.8 \pm 8.5$. The mean score of anxiety in women was higher than men. In general, about $35 \%$ of the participants in the study suffered from some degree of anxiety and there was a significant relationship between anxiety and health literacy of the participants $(\mathrm{P}>0.001)$. There was also a significant relationship between gender and anxiety, and there was a significant relationship between health literacy and education, but no significant relationship was observed in other variables.

Conclusion: Considering the importance of the role of health literacy in improving community health and controlling anxiety in the peace and stability of couples' future lives, there is a need for planning to teach anxiety management in couples, especially women, given that men suffer more from anxiety than women.

\section{* Corresponding Author:}

Mohammad Vahedian-Shahroudi, PhD.

Address: Department of Health Education and Health Promotion, School of Health, Mashhad University of Medical Sciences, Mashhad, Iran

Phone: +98 (513) 1892202

E-mail: vahedianm@mums.ac.ir 


\section{Introduction}

arriage is a very important stage of life and the basis of forming a family, which M is crucial not only for the couple but also for future generations. The couples are mentally healthy who are in harmony with themselves and their surroundings. Mental health helps individuals improve their objectives and interact respectfully with others. Mental health has a positive effect on life and reduces sensitivity to stress and anxiety [1]. Anxiety is a natural response to dangerous situations and is a warning sign, which warns of impending danger and prepares the person to deal with it. In general, anxiety is a very unpleasant and often vague generalized feeling that is accompanied by one or more physical sensations, such as an empty heart, chest tightness, palpitations, sweating, headache, etc. Almost all human beings experience some of the signs and symptoms of anxiety during their lifetime [2].

Anxiety is one of the phenomena of the $21^{\text {st }}$ century and is the result of a person's stress in all aspects of life. It is reported that $25 \%$ of those who refer to health centers in the world suffer from depression and anxiety. After investigating the rate of mental disorders, the World Health Organization (WHO) has reported that mental disorders, especially anxiety have increased, and the rate of anxiety in developing countries is $38.6 \%$ and $35.2 \%$ in developed countries $[3,4]$. Worry and anxiety are necessary for survival and guarantee the effort of human beings, but when anxiety becomes severe and leads to reduced function, it is considered a disorder [5]. Social psychologists believe that anxiety is a destructive factor that is learned through learning and role modeling; thus, it can be controlled through educational methods and role modeling [6]. Anxiety disorders are important because of the loss of function and the need to use medical resources [7].

On the one hand, the importance of health literacy has been shown at the levels of general literacy and care literacy. Health literacy is related to the capacity of individuals to meet the complex health needs of a modern community. The WHO has identified health literacy as one of the biggest determinants of health. It has also advised the countries of the world to form an association consisting of all the affected individuals to monitor and coordinate strategic activities regarding the promotion of health literacy in different communities [8]. According to studies by the American Center for Health Care Strategies, individuals with low health literacy are less likely to understand the written and spoken information provided by health professionals and follow instructions given and are in a poorer level of health. The results of the latest national study in the United States showed that $36 \%$ of adults have limited health literacy (adequate or borderline health literacy). In a study conducted in Iran, $28.1 \%$ of the subjects had adequate health literacy and $56.6 \%$ had inadequate health literacy [9]. The inclusion of educational programs and an increase in the level of health literacy of individuals seems necessary in premarital training. Health knowledge, health literacy capacities, and health behaviors during these processes will be part of the stages to reach the final destination, i.e., health [9].

Given that successful marriage can be the founder of healthy families in the community, in this study, we evaluated the relationship between anxiety and health literacy in women and men participating in premarital counseling classes as the target community to assess their anxiety and health literacy.

\section{Methods}

The present research was a descriptive-analytical cross-sectional study that was conducted in 2019 among individuals participating in premarital counseling classes in Mashhad. In order to determine the sample size according to 21 items of the Beck Anxiety questionnaire (at least 5 samples are required for each item), according to the Green formula $((\mathrm{k}+104) 3=400)$ and, considering the type of sampling, 400 samples were considered.

From all the participants in premarital classes in all comprehensive health service centers in Mashhad, 400 people were selected randomly from each health center. Eighty people from the patients referring to the center number one, 130 people from the patients referring to the center number 2, 80 people from the patients referring to the center number 3, 80 people from the patients referring to Samen health center, and 30 people from the clients of health center number 5 were randomly selected.

After obtaining the necessary permissions from the University and Comprehensive Health Service Centers of Mashhad, the considered comprehensive health centers were referred. The study inclusion criteria included mental health (no history of hospitalization or mental illness interview), literacy, and willingness to participate in the study and the exclusion criterion was incomplete questionnaires. Before giving the questionnaires to the individuals, the objectives of the study were stated and they were reassured about the confidentiality of the information. Each sample completed an informed consent form to participate in the study and questionnaires were provided to individuals. 
Data collection tools included a questionnaire consisting of 3 parts of demographic information, standard Beck Anxiety Questionnaire, and Health Literacy of Iranian Adults Questionnaire (HELIA) completed using the self-report method. The demographic information included age, gender, education, occupation, income, and consanguineous marriage. The second questionnaire was HELIA, which was designed in 2014 and includes 33 items. Its validity and reliability have been confirmed by Montazeri et al. [10]. The third questionnaire was the standard Beck Anxiety Questionnaire, which consists of 21 items with four options. The subjects mark their level of suffering from anxiety symptoms during the last week in the opposite column. The scoring method is as follows: not at all=zero, mild=one, moderate: two, and severe: three. Therefore, the range of anxiety scores will be from zero to 63 . A score of zero to 7 indicates no anxiety, 8-15 indicates mild anxiety, 16-25 indicates moderate anxiety, and 26-63 represents severe anxiety. The validity and reliability of this questionnaire have been confirmed by Kaviani et al. [11].

The data were analyzed using SPSS v. 23 and MannWhitney, Kruskal-Wallis, correlation, and regression tests at the significance level of $5 \%$. This research was done based on the principles of the Helsinki Declaration regarding medical research studies in humans and received the local research ethical code from the Mashhad University of Medical Sciences (IR.MUMS.REC.1398.158).

\section{Results}

In this study, 400 subjects participated in marriage preparation classes in Mashhad with a Mean \pm SD age of 27.8 \pm 7.2 for men and $25.8 \pm 2.5$ for women and their mean income level was $1,600,000 \pm 1,920,000$ tomans.

Table 1 shows that $61.2 \%$ of the participants in the study were women and $38.8 \%$ were men. In addition, $57.3 \%$ of the subjects had undergraduate education and $42.8 \%$ had higher diploma education. Also, 55.5\% were unemployed and $44.5 \%$ were employed and $70.2 \%$ of the subjects did not have a consanguineous marriage.

As shown in Table 1, gender had a significant relationship with anxiety $(\mathrm{P}=0.01)$ and no significant relationship was observed between education, occupation, family relationship, and anxiety $(\mathrm{P}<0.05)$.

The Mean \pm SD anxiety score was $29.8 \pm 04.3$ and the Mean \pm SD health literacy was $60.21 \pm 2$.6. The results of the linear regression test with gender and education control showed a significant relationship between health liter- acy and anxiety $(\mathrm{P}<0.001)$ and for by an increase in health literacy increase, 0.1 was added to anxiety score.Statistical results showed that $242(60.5 \%)$ of the participants had no anxiety, 44 (11\%) had mild anxiety, 98 (24.5\%) had moderate anxiety, and 16 (4\%) suffered from severe anxiety.

\section{Discussion}

This study showed a significant relationship between anxiety and health literacy i.e. the higher level of health literacy of those participating in the study, the higher anxiety they perceived. Given that the participants in this study were in a special stage of life and on the verge of marriage, having higher health literacy makes them aware of issues related to health and factors that endanger health [12]. Therefore, marriage, which has an important effect on a person's health, is considered more important and in this regard, they experience more stress and anxiety. Heidari Shams et al. [12] showed a significant and negative relationship between health literacy and health anxiety in outpatients referring to the polyclinic in Karaj; the higher the health literacy of individuals, the lower their level of health anxiety. This difference in results is probably due to health anxiety, which has different items. Also, the distinct target group and the conditions for completing the questionnaires are effective in this regard. A person with higher health literacy will suffer less health anxiety when referring to the clinic because he has the needed information. However, our study was conducted under different conditions.

The mean age of marriage in men in 2018 in Iran was 27.5 years and 23.4 years in women, and in Khorasan Razavi Province, this rate was 25.9 years for men and 21.4 years for women [13]. In our study, compared to Khorasan Razavi Province, men were almost two years and women were about 4 years older.

The present study showed that about $40 \%$ of the participants in premarital classes had some degrees of anxiety and the level of anxiety in women was higher than men, which is consistent with a study by Modara et al. [14] who investigated the mean score of anxiety in Iran through a systematic review. However, the mean score of anxiety in our study was higher than the mean score of anxiety in a study by Modara et al., which is probably due to differences in the differences in the target group. As mentioned earlier, our target group was under special conditions of marriage and the person on the eve of marriage suffers from more stress and anxiety than those in normal conditions, but in a review by Modara et al., the Iranian community with different conditions was investigated. In studies by Mendis et al. [15], Ravangard et 
Table 1. The relationship between demographic variables and anxiety and health literacy

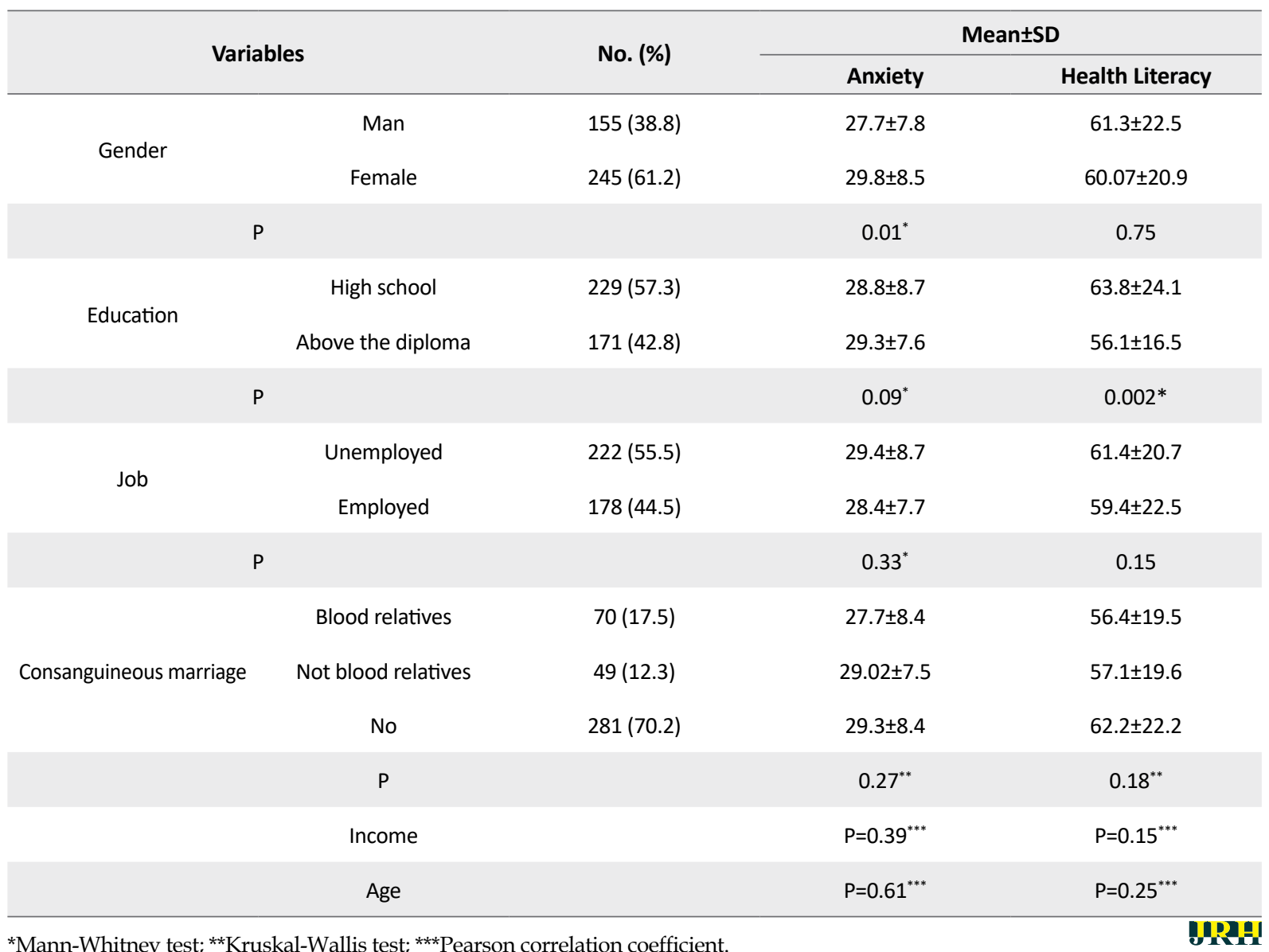

al. [16], Gardashi et al. [17], and Moradi et al. [18], the rate of anxiety in women was more than men. Today, the role of women in the social fields is increasing day by day, and the responsibility of housekeeping, child care, and marriage is burdening women. Playing these roles and balancing between them cause women to suffer high levels of anxiety and stress. Mehri et al. [19] reported more anxiety in men, which is not consistent with our study, and their study was conducted ten years before our study, which makes a difference in the culture and participation of women in the social fields leading to the difference in results. Also, different samples with different living conditions were another difference between studies; for example, as seen in large surgeries, women are more anxious than men [17].

In the present study, there was no significant relationship between anxiety and education. Consistent with our study, no significant relationship was between anxiety and education in a study by Ravangard et al. [16].

In this study, no significant relationship was found between occupation and anxiety, but in studies by Ravangard et al. [16], Asadi et al. [20], Bahrami et al. [21], and Gardashi [17], a significant relationship was found between occupation and anxiety. Regarding occupation, the classification in our study was different from other studies [16, 17, 20, 21], which may be one of the reasons for the different results. Also, these studies investigated the relationship between occupation and anxiety before surgery, which is another reason for differences in results. In addition, in our study, people were on the verge of marriage and this can be the reason for the difference because people on the verge of marriage are more anxious.

In this study, no significant relationship was detected between consanguineous marriage and anxiety, and given that no study was found on the relationship between consanguineous marriage and anxiety, the results cannot be compared. In the present study, no significant relationship was found between anxiety and income, which was not consistent with the studies by Seif Diba et al. [22] and Friedman et al. [23].

In our study, no statistically significant relationship was observed between age, gender, and health literacy, which is consistent with the studies by Charoghchian et al. [24], Khosravi et al. [25], and Mahmoudi et al. [26], but it is inconsistent with the studies by Rafieza- 
deh Gharrehtapeh et al. [27], Mohseni et al. [28], and Peyman et al. [29]. Also, no significant relationship was observed between occupation and health literacy, which is consistent with a study by Firooz et al. [30], but it is inconsistent with the studies by Abbaszadeh et al. [31] and Khosravi et al. [25].

Our study showed no significant relationship between income and health literacy, which is consistent with a study by Amiresmaili et al. [32] and it is inconsistent with a study by Javadzadeh [33] and Raisi et al. [34]. No statistically significant relationship was observed between consanguineous marriage and health literacy, for which no similar case was found for comparison. However, a statistically significant relationship was observed between education and health literacy, which is consistent with the studies by Khosravi et al. [25], Mohseni et al. [28], and Abbaszadeh et al. [31], but it is inconsistent with the studies by Charoghchian et al. [24] and Peyman et al. [29] that the differences in the target group and the level of education can indicate this difference in results.

One of the limitations of this study was a limited number of demographic variables. It is suggested to investigate more demographic variables and their relationship with anxiety in future studies. It is also suggested to investigate the relationship between health literacy and anxiety by other standard questionnaires and compare the results with the results of our study.

\section{Conclusion}

The results showed that a large number of individuals participating in premarital classes suffer from anxiety, and due to the significant relationship between health literacy and anxiety, it is suggested to address anxiety control training in premarital counseling classes. Also, health literacy should be considered as one of the objectives of organizing these classes in order to bring mental health to young couples in the light of useful training.

\section{Ethical Considerations}

\section{Compliance with ethical guidelines}

This study was approved by the Ethics Committee of Mashhad University of Medical Sciences (Code: IR.MUMS.REC.1398.158).

\section{Funding}

This study was extracted from the MA. thesis of the first author at the Department of Health Education and
Health Promotion, School of Health, Mashhad University of Medical Sciences, Mashhad (Code: 970971).

\section{Authors' contributions}

All authors equally contributed to preparing this article.

\section{Conflict of interest}

The authors declared no conflicts of interest.

\section{References}

[1] Sepehrmanesh Z, Moravveji A. [Mental health of young couples referred to premarriage consulting center of Kashan (Persian)]. Community Health. 2016;3(3):228-38. [DOI:10.1097/01. HJ.0000552753.74488.4e]

[2] Sabooteh S, Shahnazi H, Sharifi Rad GR, Hassanzadeh A. [The survey of Health Belief Model (HBM) constructs regarding pregnancy anxiety in nuliparous women (Persian)] J Health Syst Res. 2014; 9(14):1746-56. https://hsr.mui.ac.ir/ article-1-565-en.html

[3] Matarneh A, Altrawneh A. Constructing a scale of future anxiety for the students at public Jordanian universities . Int J Acad Res. 2014; 6(5):180-8. https:/ / www.researchgate.net/ profile/Ahmed-Matarneh/publication/282284074_

[4] Lambert KG. Rising rates of depression in today's society: Consideration of the roles of effort-based rewards and enhanced resilience in day-to-day functioning. Neurosci Biobehav Rev. 2006; 30(4):497-510. [PMID] [DOI:10.1097/01. HJ.0000552753.74488.4e]

[5] Maguire D, Walsh JC, Little CL. The effect of information and behavioural training on endoscopy patients' clinical outcomes. Patient Educ Couns. 2004; 54(1):61-5. [PMID] [DOI:10.1097/01.HJ.0000552753.74488.4e]

[6] Andersen BL, Kiecolt-Glaser JK, Glaser R. A biobehavioral model of cancer stress and disease course. Am Psychol. 1994; 49(5):389-404. [PMID] [DOI:10.1097/01. HJ.0000552753.74488.4e]

[7] Vancampfort D, Koyanagi A, Hallgren M, Probst M, Stubbs $\mathrm{B}$. The relationship between chronic physical conditions, multimorbidity and anxiety in the general population: A global perspective across 42 countries. Gen Hosp Psychiatry. 2017; 45:1-6. [PMID] [DOI:10.1097/01.HJ.0000552753.74488.4e]

[8] Marmot M, Friel S, Bell R, Houweling TA, Taylor S; Commission on Social Determinants of Health. Closing the gap in a generation: Health equity through action on the social determinants of health. Lancet. 2008; 372(9650):1661-9. [PMID] [DOI:10.1097/01.HJ.0000552753.74488.4e]

[9] Panahi R, Ebrahimi G, Ahmadi A. [Health literacy: A key component of controlling social determinants of health (Persian)]. J Educ Community Health. 2018; 5(1):1-3. http://jech. umsha.ac.ir/article-1-486-en.html 
[10] Montazeri A, Tavousi M, Rakhshani F, Azin SA, Jahangiri K, Ebadi M, et al. [Health Literacy for Iranian Adults (HELIA) Develoment and psychometric properties (Persian)]. Payesh 2014; 13:589-99. http:/ / payeshjournal.ir/article-1-279-en.html

[11] Kaviani H, Mousavi AS. [Psychometric properties of the Persian version of Beck Anxiety Inventory (BAI) (Persian)]. Tehran Univ Med J. 2008; 66(2):136-40. http:/ / tumj.tums.ac.ir/ article-1-641-en.html

[12] Heidari Shams J, Mohammadzadeh KA, Maher A. [Correlation between health literacy and quality of life with health anxiety in outpatient patients referred to Shahid Beheshti Specialized Polyclinic in Karaj (Persian)]. J Health Promot Manag. 2020; 9(1):1-9. http://jhpm.ir/browse.php?a_id=1109\&slc_lan $\mathrm{g}=$ en\&sid $=1 \&$ printcase $=1 \&$ hbnr $=1 \&$ hmb $=1$

[13] Global Health Data Exchange. Iran Civil Registration Recorded Births 2019-2020 [Internet]. 2020 [Updated 2020 March]. Available from: http://ghdx.healthdata.org/record/ iran-civil-registration-recorded-births-2019-2020

[14] Modara F, Sarokhani D, Valizadeh R, Sarokhani M. [The average review score of anxiety in Iran: Systematic review and metaanalysis (Persian)]. Sci j Ilam Univ Med Sci. 2017; 25(2):181-210. http://sjimu.medilam.ac.ir/article-1-3353-en.html

[15] Mendis N. Importance of general hospital in the development of mental health care. World Psychiatry. 2003; 2(2):100-2. [PMID]

[16] Ravangard R, Bastani P, Moradi A, Mahdiehsadat A. [Factors affecting the preoperative anxiety from the patients ' perspective (Persian)]. Daneshvar Med. 2016; 24(3):61-70. http:// daneshvarmed.shahed.ac.ir/article_1740.html?lang=en

[17] Ghardashi F. [Factors affecting preoprative anxiety (Persian)]. Koomesh. 2007; 8(3):123-30. http://koomeshjournal. semums.ac.ir/article-1-35-en.html

[18] Moradi M, Zeighami R, Mohammadi S, Sarichlu M E. [Psychiatric status in couples attending training courses before marriage (Persian)]. J Nurs Educ. 2013; 1(3):19-26. http:/ /ijpn. ir/article-1-186-en.html

[19] Mehri A, Sedighy Some-Koochak Z. [Assessment of mental health status and some related factors among students of Sabzevar Universities in 2010 (Persian)]. Med Sci J Islamic Azad Univ-Tehran Med Branch. 2012; 21(4):293-304. http://tmuj. iautmu.ac.ir/article-1-530-fa.html

[20] Asadi M, asadzandi M, ebadi A. Effects of spiritual care based on GhalbSalim nursing model in reducing anxiety of patients undergoing CABG surgery. Iran J Crit Care Nurs. 2014; 7(3):142-51. http://jccnursing.com/article-1-288-fa.html

[21] Bahrami N, Soleimani MA, Erjini Z, Shraifnia H, Masoodi $R$, Shahrokhi A. [The effect of nursing process - based care on patients' anxiety of candidates for women's elective surgery (Persian)]. Iran J Nurs. 2012; 25(77):30-9. http://ijn.iums.ac.ir/ article-1-1292-en.html

[22] Seif D, Alborzi S, Alborzi S. [Effect of some affective and demographic variables on life satisfaction of infertile women (Persian)]. J Reprod Infertil. 2001; 2(4):66-74. https:/ /www.jri. ir/article/ 69

[23] Freedman AM, Kaplan HI, Sadock BJ. Modern synopsis of comprehensive textbook of psychiatry, II. Philadelphia: Williams \& Wilkins; 1976. https://books.google.com/books/ about/Modern_Synopsis_of_Comprehensive_Textboo html?id=NnRVsU2G_jQC
[24] Charoghchian Khorasani E, Peyman N, Sahebkar M Moghzi M. Investigating health literacy in patients with type 2 diabets referring to the health houses of Chenaran in 2016. J N Khorasan Univ Med Sci. 2017; 9(2):183-91. http://journal. nkums.ac.ir $/$ browse.php?a_id=1198\&sid=1\&slc_lang=en

[25] Khosravi AR, Ahmadzadeh K, Arastoopoor S, Tahmasbi R. [Health literacy levels of diabetic patients referred to Shiraz health centers and its effective factors (Persian)]. Health Inf Manage. 2015; 12(2):194-205. https://www.sid.ir/en/Journal/ViewPaper.aspx?ID=578175

[26] Mahmoodi H, Negarandeh R, Javaheri M, Sharifi P, Ghanei $\mathrm{R}$, AminPour A, et al. [Examining the relation of health literacy with outcomes of diabetes among type 2 patients in Saqez (Persian)]. Nurs Midwifery J. 2014; 12(1):56-62. https:/ / unmf.umsu.ac.ir/article-1-1811-en.html

[27] Rafiezadeh Gharrehtapeh S, Tabarsy B, Hassanjani S, Razavi M, Amjadi M, Hojjati H. [The relationship between health literacy and self-efficacy in patients with type ii diabetes admitted to Gorgan Diabetes Clinic in 2014 (Persian)]. J Diabetes Nurs. 2015; 3(2):30-42. http://jdn.zbmu.ac.ir/article-1-111-fa.html

[28] Mohseni M, Khanjani N, Iranpour A, Tabe R, Borhaninejad V R. [The relationship between health literacy and health status among elderly people in Kerman (Persian)]. Salmand. 2015 10(2):146-55. http:/ / salmandj.uswr.ac.ir/article-1-790-en.html

[29] Peyman N. [Investigating the status of health literacy among health providers of rural area (Persian)]. J Health Lit. 2016; 1(1):46-52. https://literacy.mums.ac.ir/article_10976 d235cb6d65e2095e18a8e76ef8a748c6.pdf

[30] Firooz M, Hosseini SJ, Mazlom SR, Hasan Zadeh F, Kimiyaee SA. [Self-care of patient with diabetes type II (Persian)] J Sabzevar Univ Med Sci. 2016; 22(6):1018-25. http://jsums. medsab.ac.ir/article_786_en.html

[31] Abbaszadeh Bazzi M, Karimiaval M. [Relationship between health literacy and self-care behaviors in diabetic patients type ii referred to the center of diabetes control and prevention in Zabol (Persian)]. J Health Lit. 2018; 3(1):10-9. [DOI:10.1097/01.HJ.0000552753.74488.4e]

[32] Amiresmaili M, Nekoei Moghadam M, Saberi anari S, Sadeghi A, Saber M, Taheri G, et al. Study of health literacy level of women referring to health centers-2010. J North Khorasan Univ Med Sci. 2014; 5(5):1071-8. http://journal.nkums.ac.ir/ article-1-271-en.htm

[33] Javadzade SH, Shaarifi Rad G, Reisi M, Tavassoli E, Rajati F. Health literacy among adults of Isfahan, Iran. J Health Syst Res. 2013; 9(5):540-9. https://hsr.mui.ac.ir/browse.php?a id $=630 \&$ sid $=1 \&$ slc_lang $=$ en

[34] Reisi M, Javadzade SH, Mostafavi F, Sharifirad G, Radjati F, Hasanzade A. Relationship between health literacy, health status, and healthy behaviors among older adults in Isfahan Iran. J Edu Health Promot. 2012; 1:31. https://www.jehp net $/$ article.asp?issn $=2277-9531$; year $=2012$; volume $=1$;issue $=1$ spage $=31$; epage $=31$; aulast $=$ Reisi 
This Page Intentionally Left Blank 